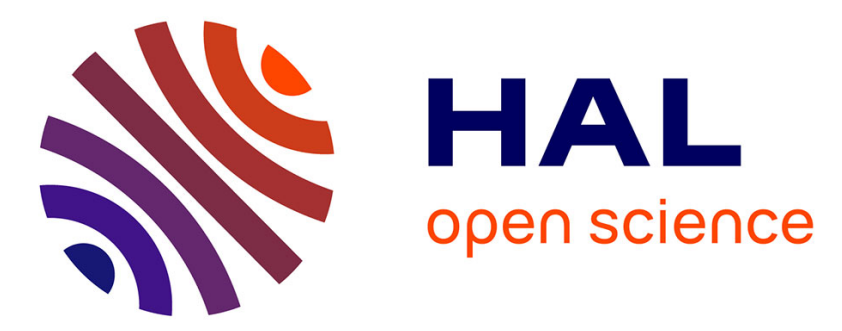

\title{
Dehalogenation reaction photocatalyzed by homoleptic copper( i ) complexes associated with strongly reductive sacrificial donors
}

Lea Gimeno, Clémence Queffélec, Kevin Mall Haidaraly, Errol Blart, Yann Pellegrin

\section{To cite this version:}

Lea Gimeno, Clémence Queffélec, Kevin Mall Haidaraly, Errol Blart, Yann Pellegrin. Dehalogenation reaction photocatalyzed by homoleptic copper( i ) complexes associated with strongly reductive sacrificial donors. Catalysis Science \& Technology, 2021, 11 (18), pp.6041-6047. 10.1039/d1cy01209f . hal-03419918

\section{HAL Id: hal-03419918 \\ https://hal.science/hal-03419918}

Submitted on 11 Nov 2021

HAL is a multi-disciplinary open access archive for the deposit and dissemination of scientific research documents, whether they are published or not. The documents may come from teaching and research institutions in France or abroad, or from public or private research centers.
L'archive ouverte pluridisciplinaire HAL, est destinée au dépôt et à la diffusion de documents scientifiques de niveau recherche, publiés ou non, émanant des établissements d'enseignement et de recherche français ou étrangers, des laboratoires publics ou privés. 


\title{
Dehalogenation reaction photocatalyzed by
}

\section{homoleptic copper(I) complexes associated with}

\section{strongly reductive sacrificial donors}

Lea Gimeno, ${ }^{a}$ Clémence Queffélec, ${ }^{a} *$ Kevin Mall Haidaraly, ${ }^{a}$ Errol Blart, ${ }^{a}$ Yann Pellegrin ${ }^{a} *$

CEISAM, UMR 6230, Université de Nantes, CNRS, 2 chemin de la Houssinière, Nantes F44000, France

KEYWORDS. reductive quenching $\bullet$ homoleptic copper(I) complexes $\bullet$ photochemistry $\bullet$ benzimidazoline $\bullet$ sacrificial donors

\begin{abstract}
In order to perform challenging reduction reactions with light, at low cost and low toxicity, we aim at using for the first time a reductive quenching cycle with a simple, strongly colored homoleptic copper(I) complex $\quad\left[\mathrm{Cu}(\mathrm{dipp})_{2}\right]^{+} \quad(\mathrm{dipp}=$ 2,9-diisopropyl-1,10phenanthroline). Complexes of this family being weak photo-oxidants, we specifically designed and synthesized powerful, recyclable sacrificial electron donors D. We demonstrate that, during irradiation with LED in presence of $\mathrm{D}$, the strong reductant $\left[\mathrm{Cu}(\operatorname{dipp})_{2}\right]^{0}$ is efficiently photogenerated. Further, we present the first photochemical reaction using photo-generated $\left[\mathrm{Cu}(\mathrm{dipp})_{2}\right]^{0}$ and evidence that the kinetics of the overall reaction are strongly affected by the oxidation potential of the sacrificial donor $\mathrm{E}\left(\mathrm{D}^{+} / \mathrm{D}\right)$. Adapting the thermodynamics of sacrificial
\end{abstract}


donors $\mathrm{D}$ and $\left[\mathrm{Cu}(\mathrm{dipp})_{2}\right]^{+}$has thus allowed to unlock a brand new concept, giving access to cheap, non-toxic solar light generated very strong reductive power.

\section{Introduction}

Organic photochemistry is a very active research field where light is used to drive challenging reactions (involving in particular reactive radicals) in mild, green and sustainable conditions, with a high tolerance towards functional groups. ${ }^{1,2}$ Most of the time, the addition of a photosensitizer PS in the reaction mixture is necessary. While heavy metal (e.g. ruthenium or iridium) based complexes are frequently used as PS, copper(I) complexes are playing a more and more important role in modern photochemistry as cheaper, less noxious and efficient photosensitizers. ${ }^{3-5}$ In the context of organic photochemistry, there are mainly two sorts of $\mathrm{Cu}(\mathrm{I})$ complexes: homoleptic complexes of the general formula $\left[\mathrm{Cu}^{\mathrm{I}}(\mathrm{NN})_{2}\right]^{+}(\mathrm{PSCu})$ and heteroleptic ones of the general formula $\left[\mathrm{Cu}^{\mathrm{I}}(\mathrm{PP})(\mathrm{NN})\right]^{+}\left(\mathrm{PS}_{\mathrm{Cu}}\right)$ where $\mathrm{NN}$ is a sterically burdened chelating diimine ligand and PP a bulky bisphosphine ligand. ${ }^{6}$ Both sorts of complexes are abundantly used in the frame of oxidative quenching based processes ${ }^{7}$ because they exhibit a very strong photoreductive power (e.g. $-1.43 \mathrm{~V}$ vs. SCE for $\left[\mathrm{Cu}(\mathrm{dap})_{2}\right]^{+8,9}$ and -1.44 for $\mathrm{Cu}($ Xantphos $\left.)(\mathrm{dmp})^{+}\right)^{10}$ and can react with a variety of electron acceptors, once in their excited state.

Conversely, $\mathrm{Cu}(\mathrm{I})$ complexes are less used in the frame of reductive quenching based processes. ${ }^{7}$ Several examples of photochemical cycles involving the reductive quenching of the excited state of heteroleptic $\mathrm{Cu}(\mathrm{I})$ complexes can be found. ${ }^{11-15}$ In those examples, RQ was advantageously used to generate the reduced state $\left[\mathrm{Cu}^{\mathrm{I}}(\mathrm{PP})\left(\mathrm{NN}^{\bullet}\right)\right]^{0}$ in presence of an electron donor (e.g. triethylamine). This reduced species is a very strong reductant (from ca. $-1.6 \mathrm{~V}$ to $-1.8 \mathrm{~V}$ vs. 
$\mathrm{SCE})^{13,16,17}$ better or equal to many ruthenium and iridium PS in the same conditions (e.g. $-1.3 \mathrm{~V}$ vs. SCE for $\left[\mathrm{Ru}(\mathrm{bpy})_{3}\right]_{2}{ }^{+18}$ and $-1.4 \mathrm{~V}$ vs. SCE for $\left.\left[\operatorname{Ir}\left(\mathrm{dFCF}_{3} \text { ppy }\right)_{2}(\mathrm{bpy})\right]^{+}\right) .{ }^{19}$

RQ with homoleptic $\mathrm{Cu}(\mathrm{I})$ complexes $\mathrm{PS}_{\mathrm{Cu}}$ would present many advantages too for the following reasons: they feature very negative reduction potentials like the heteroleptic parent complexes, making them equally potent reductants after RQ (e.g. $-1.6 \mathrm{~V}$ vs. SCE for $\left[\mathrm{Cu}(\operatorname{dipp})_{2}\right]^{+}$where dipp stands for 2,9-diisopropyl-1,10-phenanthroline). Second, they exhibit a broad absorption band in the visible, where usual efficient $\mathrm{PS}_{\mathrm{Cu}}$, are less efficient light collectors (Figure S1) although significant progresses have been made to red-shift their absorption spectrum. ${ }^{20-23}$ Third, $\left[\mathrm{Cu}(\mathrm{NN})_{2}\right]^{+}$complexes are easier easy to prepare and more stable in the long term than $[\mathrm{Cu}(\mathrm{PP})(\mathrm{NN})]^{+}$ones. ${ }^{24,25}$ Finally, the excited state of $\mathrm{PS}_{\mathrm{Cu}}$ is sufficiently long-lived ${ }^{26}$ to ensure reactivity with donor $\mathrm{D}$.

However, reports of RQ processes involving $\mathrm{PS}_{\mathrm{Cu}}$ are a lot rarer than with $\mathrm{PS}_{\mathrm{Cu}}$, because the excited state of homoleptic copper(I) complexes is a weak photo-oxidant, unable to react with usual electron donors. ${ }^{27-29}$ Efforts have been made to increase the photo-oxidizing strength of $\mathrm{PS}_{\mathrm{Cu}}$ (quantitatively described by $\mathrm{E}\left(\mathrm{PS}_{\mathrm{Cu}}{ }^{*} / \mathrm{PS}_{\mathrm{Cu}}{ }^{-}\right)$) by shifting the reduction potential $\mathrm{E}\left(\mathrm{PS}_{\mathrm{Cu}} / \mathrm{PS}_{\mathrm{Cu}}{ }^{-}\right)$to less negative values. This strategy proved to be efficient to implement RQ but the reductive power of $\mathrm{PS}_{\mathrm{Cu}}$ - was sacrificed. Another, more recent strategy is based on increasing the energy of the excited state. Improvements of $\left.\mathrm{E}_{\left(\mathrm{PS}_{\mathrm{Cu}}\right.}{ } / \mathrm{PS}_{\mathrm{Cu}}{ }^{-}\right)$are reported without altering $\mathrm{E}\left(\mathrm{PS}_{\mathrm{Cu}} / \mathrm{PS}_{\mathrm{Cu}}{ }^{-}\right)$. A different, complementary approach is to shift the oxidation potential of the electron donor D to less positive values. This method was successfully used by McMillin et al.. ${ }^{30,31}$ Several ferrocene derivatives featuring very low oxidation potentials were used as D in presence of $\left[\mathrm{Cu}(\mathrm{dipp})_{2}\right]^{+}$or $\left[\mathrm{Cu}(\mathrm{dpp})_{2}\right]^{+}$(where dpp stands for 2,9-diphenyl-1,10-phenanthroline) as $\mathrm{PS}_{\mathrm{Cu}}$. A minimum experimental driving force of $300 \mathrm{meV}$ for RQ to occur between $\mathrm{PS}_{\mathrm{Cu}}{ }^{*}$ and 
D was determined on this occasion. However, the ferrocinium/ferrocene couples are reversible and a fast charge recombination takes place between $\mathrm{D}^{+}$and $\mathrm{PS}_{\mathrm{Cu}}{ }^{-}$, preventing to accumulate the latter and to manage a reduction reaction with a substrate. Trials involving $\left[\mathrm{Cu}(\mathrm{dpp})_{2}\right]^{+}$with irreversible electron donors (dithionite, dihydroxyquinone) were unsuccessful owing to their oxidation potential being too positive with respect to $\mathrm{E}\left(\mathrm{PS}_{\mathrm{Cu}}{ }^{*} / \mathrm{PS}_{\mathrm{Cu}}{ }^{-}\right){ }^{32}$ It thus appears relevant to develop electron donors $\mathrm{D}$ such that $\mathrm{D}$ is irreversibly oxidized and $\mathrm{E}\left(\mathrm{D}^{+} / \mathrm{D}\right)$ is shifted at very low anodic potential. RQ can be basically described as a photo-induced electron transfer from D to $\mathrm{PS}_{\mathrm{Cu}}{ }^{*}$. The thermodynamics of the reaction thus depend on both species. In order to refine our objectives, we focus on implementing RQ with simple homoleptic complex $\left[\mathrm{Cu}(\mathrm{dipp})_{2}\right]^{+}$ (hereafter named $\mathrm{C} 1$ ). The latter was chosen because it features a very negative reduction potential (ca. $-1.6 \mathrm{~V}$ vs. SCE) ${ }^{17,33}$ and one of the most intense absorption band in the visible, for a homoleptic copper(I) complex $\left(\varepsilon 455 \mathrm{~nm}=\right.$ ca. $6700 \mathrm{M}^{-1} \cdot \mathrm{cm}^{-1}$, figure S1). Additionally, $\mathrm{C} 1$ is stable, with a long excited state lifetime (200 ns in degassed THF) ${ }^{17}$ Knowing that for $\mathrm{C} 1$, the photo-oxidation potential $\mathrm{E}\left(\mathrm{Cl}^{*} / \mathrm{Cl}^{-}\right)$is equal to $0.46 \mathrm{~V}$ vs. SCE in THF, relevant target $\mathrm{D}$ should exhibit an irreversible oxidation step at $\mathrm{E}\left(\mathrm{D}^{+} / \mathrm{D}\right)=0.16 \mathrm{~V}$ vs. SCE at least.

Benzimidazoline donors, epitomized by famous BIH (Scheme 1) fulfill almost all required parameters. However, $\mathrm{E}\left(\mathrm{BIH}^{+} / \mathrm{BIH}\right)$ is too positive to allow RQ with common homoleptic complexes. ${ }^{34}$ The potential of benzimidazoline donors can however be efficiently tuned by chemical engineering. Jin-Pei Chen et al. ${ }^{35}$ successfully demonstrated that $\mathrm{E}\left(\mathrm{BIH}^{+} / \mathrm{BIH}\right)$ could be substantially lowered when electron donating groups are tethered either to cycles A or B (Scheme 1). Aiming at implementing RQ involving $\mathrm{C} 1$ and a benzimidazoline donor, we thus prepared new $\mathrm{BI}_{1} \mathrm{H}$ and $\mathrm{BI}_{2} \mathrm{H}$ donors with multiple electron rich methoxy groups grafted on cycles A and B of the BIH molecular skeleton (Scheme 1). 


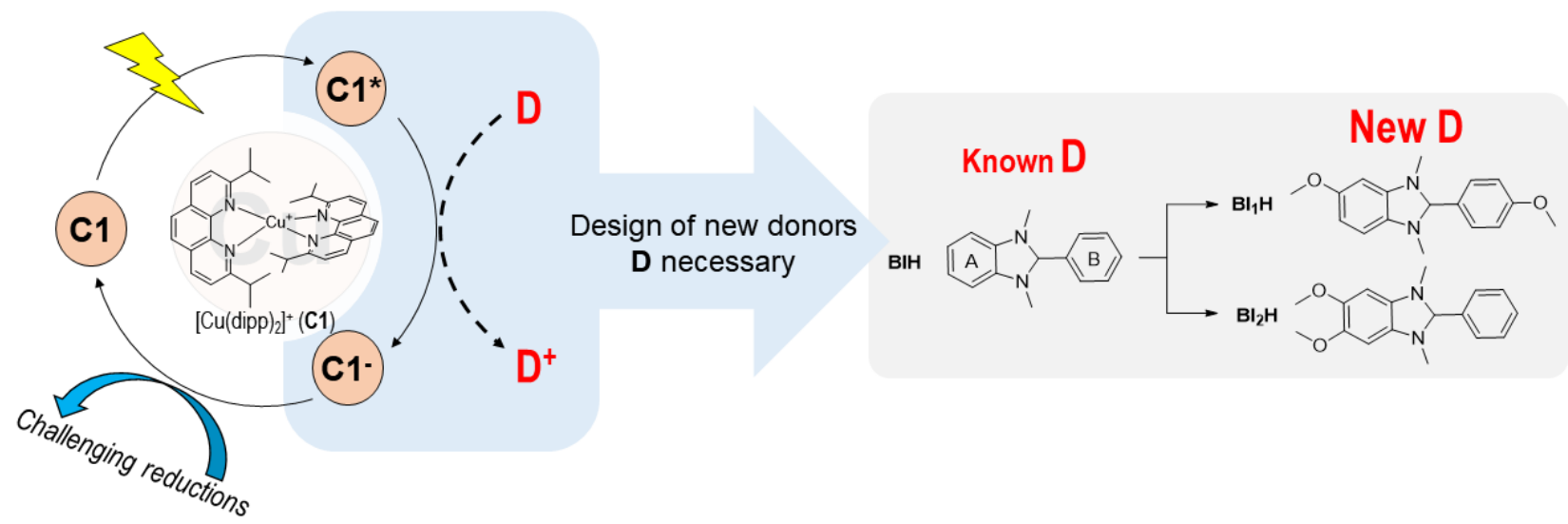

Scheme 1. Illustration of the strategy developed in this contribution: to implement for the first time a reductive quenching of the excited state of homoleptic copper(I) complexes by using benzimidazoline donors

In this contribution, we focus on the design of new donors $\mathrm{D}$ based on a benzimidazoline molecular frame such that RQ with benchmark $\mathrm{C} 1$ is thermodynamically possible. We implement for the first time the reductive quenching of the excited state of a strongly colored homoleptic copper(I) complex, by using specifically designed benzimidazoline donors and mild light sources. Very powerful and cheap reductant $\left[\mathrm{Cu}(\operatorname{dipp})\left(\operatorname{dipp}^{\bullet-}\right)\right]^{0}$ is photo-generated and accumulated in the photolyzed medium, and this unprecedented process is used to achieve a challenging reduction reaction in the field of organic photochemistry.

Efficient sacrificial donors D should be colorless (in order not to interfere with light collection by $\mathrm{C} 1)$, exhibit an oxidation at a sufficiently low potential $\mathrm{E}\left(\mathrm{D}^{+} / \mathrm{D}\right)$ to allow photo-induced electron transfer from $\mathrm{D}$ to $\mathrm{Cl}^{*}$, and the oxidation must be irreversible to avoid counterproductive charge recombination between $\mathrm{D}^{+}$and $\mathrm{C1}^{-}$. Indeed, McMillin et al. successfully evidenced RQ between $\mathrm{C} 1^{*}$ and ferrocene donors ${ }^{30,31}$ but the reversibility of the 
ferrocinium/ferrocene couples prevented $\mathrm{C1}^{-}$to accumulate and use its strong reductive power in further reactions. However, this work permitted to determine that a minimum driving force of $300 \mathrm{meV}$ is necessary to drive RQ. Knowing that for $\mathrm{C} 1$, the photo-oxidation potential $\mathrm{E}\left(\mathrm{C}^{*} / \mathrm{C1}^{-}\right)$is equal to $0.46 \mathrm{~V}$ vs. SCE in THF, relevant target $\mathrm{D}$ should exhibit $\mathrm{E}\left(\mathrm{D}^{+} / \mathrm{D}\right)=0.16$ V vs. SCE at least. Benzimidazoline donors, epitomized by famous BIH (Scheme 1) fulfill all required parameters but their oxidation potential must be adapted to the low photo-oxidation power of $\mathrm{C} 1$. Jin-Pei Chen et al. ${ }^{35}$ successfully demonstrated that $\mathrm{E}\left(\mathrm{BIH}^{+} / \mathrm{BIH}\right)$ could be substantially lowered when electron donating groups are tethered either to cycles A or B (Scheme 1). Aiming at implementing RQ involving $\mathrm{C} 1$ and a benzimidazoline donor, we thus prepared new $\mathrm{BI}_{1} \mathrm{H}$ and $\mathrm{BI}_{2} \mathrm{H}$ donors with multiple electron rich methoxy groups grafted on cycles $\mathrm{A}$ and $\mathrm{B}$ of the $\mathrm{BIH}$ molecular skeleton (Scheme 1). $\mathrm{BI}_{1} \mathrm{H}$ was synthesized using the procedure developed by Jin-Pei Cheng et al, ${ }^{35}$ using dithionite as a reductant agent and paraanisaldehyde. The same strategy was envisioned in the case of $\mathrm{BI}_{2} \mathrm{H}$. However, in order to save unnecessary synthesis steps, we started with 4,5-dimethoxy-1,2-dinitrobenzene 1' (easily obtained in gram scale ${ }^{36}$ instead of 4,5-dimethoxynitroaniline), in the same above experimental conditions, with dithionite and benzaldehyde 2'. Rewardingly, after 7 days of reaction, the desired benzimidazole derivative 3' was isolated with $90 \%$ yield. Both precursors 3 and 3' could be obtained in gram scale starting with $5 \mathrm{~g}$ of 1 or 1 '. Then, the imidazole nitrogen atoms were methylated in presence of methyl iodide and target compound $\mathrm{BI}_{1} \mathrm{H}$ and $\mathrm{BI}_{2} \mathrm{H}$ were finally obtained as colorless powders, by reduction of $\left[\mathrm{B}_{\mathrm{I}} 1^{+}, \mathrm{I}^{-}\right]$or $\left[\mathrm{BI}_{2}{ }^{+}, \mathrm{I}^{-}\right]$with $\mathrm{NaBH}_{4}$, respectively (Scheme 2 and detailed procedures in the SI). 


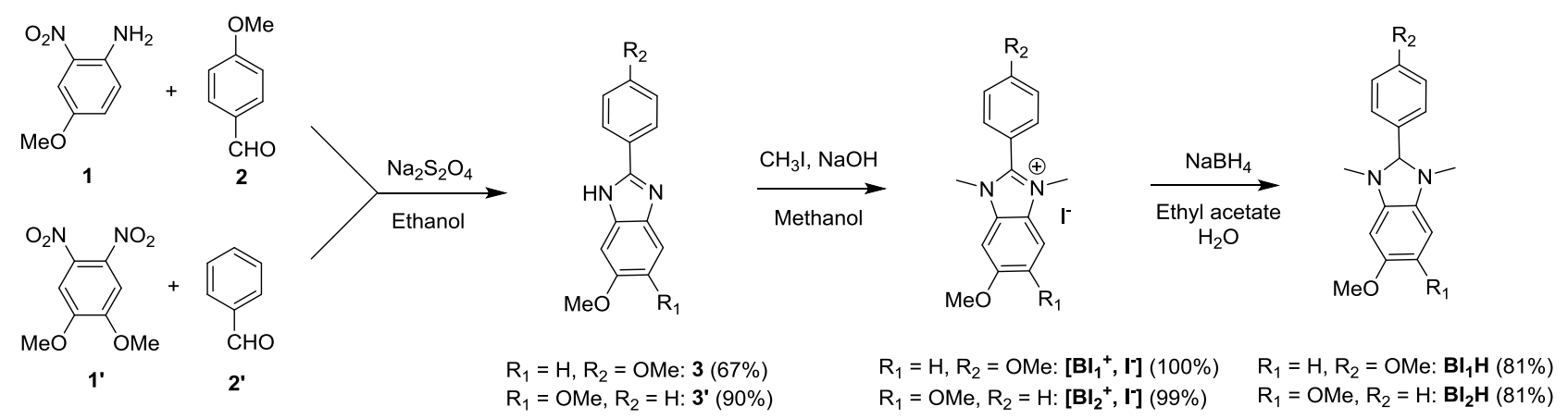

Scheme 2. Synthesis of $\mathrm{BI}_{1} \mathrm{H}$ and $\mathrm{BI}_{2} \mathrm{H}$ sacrificial donors

The synthesis of $\mathrm{BI}_{1} \mathrm{H}$ and $\mathrm{BI}_{2} \mathrm{H}$ thus proceeded smoothly: it is reproducible, scalable, does not require to isolate unstable species nor drastic conditions for the reduction of the nitro groups, and the overall yield of the synthesis $\left(72 \%\right.$ over 3 steps for $\mathrm{BI}_{2} \mathrm{H}$ and $55 \%$ for $\left.\mathrm{BI}_{1} \mathrm{H}\right)$ is satisfying.

Both $\mathrm{BI}_{1} \mathrm{H}$ and $\mathrm{BI}_{2} \mathrm{H}$ are stable as powders (shelf stability: several months). ${ }^{1} \mathrm{H}$ NMR studies of $\mathrm{BI}_{1} \mathrm{H}$ and $\mathrm{BI}_{2} \mathrm{H}$ in aerated deuterated THF (Figures $\mathrm{S} 2$ and $\mathrm{S} 3$ ) revealed a mild degradation of $\mathrm{BI}_{\mathrm{m}} \mathrm{H}$ after 20 hours (ca. 10\%) in ambient conditions. A fine precipitate was observed, collected and identified as $\mathrm{BI}_{1}^{+}$(counter-anion undetermined) and $\mathrm{BI}_{2}^{+}$(counter-anion undetermined), probably resulting from $\mathrm{O}_{2}$ promoted oxidation of corresponding benzimidazolines. Importantly, no degradation was monitored for at least 3 hours, namely the duration of the photolysis trials.

Cyclic voltammetry experiments were conducted for $\mathrm{BI}_{1} \mathrm{H}$ and $\mathrm{BI}_{2} \mathrm{H}$ in dry THF (cyclovoltammograms displayed in Figures S4-5). The forward scans feature in both cases an intense oxidation wave associated to $\mathrm{BI}_{\mathrm{m}} \mathrm{H} \rightarrow \mathrm{BI}_{\mathrm{m}} \mathrm{H}^{+}$. A less intense cathodic wave appears on the reverse scan, indicating partial reversibility of the $\mathrm{BI}_{\mathrm{m}} \mathrm{H}^{+} / \mathrm{BI}_{\mathrm{m}} \mathrm{H}$ couple. In presence of one equivalent of triethylamine (TEA), the cathodic waves disappear (Figures S4-5). Indeed, 
oxidation of $\mathrm{BI}_{\mathrm{m}} \mathrm{H}$ into $\mathrm{BI}_{\mathrm{m}} \mathrm{H}^{\bullet+}$ is then followed by deprotonation of the latter into $\mathrm{BI}_{\mathrm{m}}{ }^{\bullet}$, a strongly reductive species (Figure S6). Assigning a reliable potential value for an irreversible process is not straightforward. Following Nicewicz and Vullev's lead, ${ }^{26}$ we choose to quantify $\mathrm{E}\left(\mathrm{BI}_{\mathrm{m}} \mathrm{H}^{+} / \mathrm{BI}_{\mathrm{m}} \mathrm{H}\right)$ in our conditions as the half-peak potential $\mathrm{E}_{\mathrm{p} / 2}$ in absence of TEA (Table 1), considering that the $\mathrm{CE}$ character of $\mathrm{BI}_{\mathrm{m}} \mathrm{H}$ oxidation in basic medium distorts the oxidation waves. Edge potentials $\mathrm{E}_{\mathrm{e}}$ (where faradaic current starts to grow, indicating the beginning of the donors electroactivity) are given too. As expected, the values of $\mathrm{E}_{\mathrm{p} / 2}$ for both $\mathrm{BI}_{1} \mathrm{H}$ and in particular $\mathrm{BI}_{2} \mathrm{H}$ are significantly less positive than the case of benchmark $\mathrm{BIH}$ due to the electron donating effect of the methoxy groups (Table 1, figures $\mathrm{S} 4-\mathrm{S} 5$ ). $\mathrm{BI}_{2} \mathrm{H}$ notably features a remarkably low $\mathrm{E}_{\mathrm{p} / 2}$ of $0.13 \mathrm{~V}$ vs. SCE, strongly shifted towards less positive potentials by ca. $300 \mathrm{mV}$ compared to previously published benzimidazoline donors. ${ }^{35}$

Table 1. Electrochemical data and deduced driving forces for electron transfer in the frame of RQ. Potentials are given vs. SCE. Cyclic Voltammetry has been recorded in THF with tetrabutylammonium hexafluorophosphate $0.1 \mathrm{M}$.

\begin{tabular}{|c|c|c|c|}
\hline & $\mathrm{E}_{\mathrm{p} / 2}\left(\mathrm{BI}_{\mathrm{m}} \mathrm{H}^{+} / \mathrm{BI}_{\mathrm{m}} \mathrm{H}\right)$ & $\mathrm{E}_{\mathrm{e}}\left(\mathrm{BI}_{\mathrm{m}} \mathrm{H}^{+} / \mathrm{BI}_{\mathrm{m}} \mathrm{H}\right)$ & $\Delta \mathrm{G}_{\mathrm{RQ}}(\mathrm{eV})^{\lfloor\mathrm{a}\rfloor}$ \\
\hline $\mathrm{BI}_{1} \mathrm{H}$ & 0.38 & 0.2 & -0.08 \\
\hline $\mathrm{BI}_{2} \mathrm{H}$ & 0.13 & 0.0 & -0.33 \\
\hline
\end{tabular}

${ }^{[a]}$ Calculated using the equation $\Delta \mathrm{GRQ}=-\mathrm{F} \cdot\left[\mathrm{E}\left(\mathrm{C} 1^{*} / \mathrm{C1}^{-}\right)-\mathrm{E}_{\mathrm{p} / 2}\left(\mathrm{BI}_{\mathrm{m}} \mathrm{H}^{+} / \mathrm{BI}_{\mathrm{m}} \mathrm{H}\right)\right]$ with $\mathrm{E}\left(\mathrm{C} 1^{*} / \mathrm{Cl}^{-}\right)$ $=0.46 \mathrm{~V}$ vs. SCE. $\mathrm{E}\left(\mathrm{C} 1 * / \mathrm{C}^{-}\right)$was estimated with the Rehm and Weller equation $\mathrm{E}\left(\mathrm{C} 1^{*} / \mathrm{C1}^{-}\right)=$ $\mathrm{E}\left(\mathrm{C} 1 / \mathrm{C}^{-}\right)+\mathrm{E}^{00}$, where $\mathrm{E}\left(\mathrm{C} 1 / \mathrm{C}^{-}\right)=-1.65 \mathrm{~V}$ vs. SCE (Figure $\left.\mathrm{S} 7\right)$ and $\mathrm{E} 00=2.11 \mathrm{eV} .^{17}$ 
We next monitored the evolution of the UV-Vis spectrum of $\mathrm{C} 1$ in THF, in presence of benzimidazoline donors and triethylamine, under irradiation by a blue LED. For both $\mathrm{BI}_{1} \mathrm{H}$ and $\mathrm{BI}_{2} \mathrm{H}$, the solution darkened and a fine powder precipitated. Light scattering prevents to record proper UV-Vis spectra and the same experiment is thus performed in acetonitrile where photolyzed solutions remained transparent. In those conditions, a broad band at $575 \mathrm{~nm}$ quickly rises (Figures S8 and S9) which compared well with the spectrum of $\mathrm{C1}^{-}$obtained by reductive spectro-electrochemistry (figure S10). We thus assigned the monitored spectral changes to the photo-induced formation of $\mathrm{Cl}^{-}$, proving that $\mathrm{C}^{*}$ is reductively quenched by $\mathrm{BI}_{1} \mathrm{H}$ and $\mathrm{BI}_{2} \mathrm{H}$ despite the rather weak estimated driving force for $\mathrm{BI}_{1} \mathrm{H}$ (Table 1). Stern-Volmer analysis (Figure S11) allowed to estimate the rate constants for RQ at $\mathrm{k}_{\mathrm{RQ}}=4.4 \times 10^{7}$ and $1.4 \times 10^{8} \mathrm{~s}^{-1} \cdot \mathrm{M}^{-1}$ when the quencher is $\mathrm{BI}_{1} \mathrm{H}$ and $\mathrm{BI}_{2} \mathrm{H}$ respectively. RQ is faster with $\mathrm{BI}_{2} \mathrm{H}$ than $\mathrm{BI}_{1} \mathrm{H}$ thanks to the improved driving force for the electron transfer (Table 1). Nevertheless, the kinetics are sluggish compared to the case of a heteroleptic copper(I) complex in presence of $\mathrm{BIH}^{25}$ In the latter situation however, the Gibbs free energy for the electron transfer is much larger than in our case, and it is known that RQ with copper(I) complexes is particularly demanding from the thermodynamic point of view because of the large reorganization energy which is expected in the transformation from $\mathrm{C}^{*}$ to $\mathrm{C}^{-32}$.

Achieving reductive quenching of $\mathrm{C}^{*}$ with an irreversible electron donor not only allows to generate the strong reductant $\mathrm{Cl}^{-}$but also permits to accumulate the latter in the photolyzed medium, opening a new avenue towards the photo-assisted reduction of challenging substrates. This encouraged us to implement a photochemical reaction involving the $\mathrm{BI}_{\mathrm{m}} \mathrm{H} / \mathrm{C}$ 1 couple in a demanding reductive process. We selected the photo-assisted dehalogenation of aromatic 
compounds which is known to be challenging, ${ }^{13,39}$ and paves the way towards fruitful aryl radical chemistry. $15,39,40$

We chose to start with 4-bromo-benzophenone Bzp- $\mathrm{Br}$ as substrate $\left(\mathrm{E}_{\mathrm{p} / 2}=-1.62 \mathrm{~V}\right.$ vs. $\mathrm{SCE}$, Figure S12) and investigate the photogeneration of plain benzophenone Bzp-H in degassed THF and in presence of $\mathrm{C} 1$, TEA and benzimidazoline donors with visible light, in the same conditions described by Michelet et al. (blue LED, $450 \mathrm{~nm}){ }^{13}$ The photolyzed mixture is regularly monitored by gas chromatography. Knowing that copper(I) complexes are strong photo-reductants, we first confirmed that $\mathrm{C} 1$ was unable to reduce $\mathrm{Bzp}-\mathrm{Br}$ via the well-known oxidative quenching process (Table 2 , entry 1 ). On the other hand, when a mixture of C1, TEA, $\mathrm{BI}_{1} \mathrm{H}$ and Bzp-Br was irradiated (entry 2) the solution darkened and a fine white powder precipitates. The conversion gradually increases with time to reach a final value of $95 \%$ after 3 hours irradiation. The precipitate and the filtrate were separated by centrifugation. ${ }^{1} \mathrm{H}$ NMR of the filtrate confirms that all Bzp-Br has been consumed and the signals of Bzp-H are clearly observed, while the precipitate is identified as $\left[\mathrm{BI}_{1}{ }^{+}, \mathrm{Br}^{-}\right]$by ${ }^{1} \mathrm{H}$ NMR (Figure S13). When the same experiment is conducted with $\mathrm{BI}_{2} \mathrm{H}$ instead of $\mathrm{BI}_{1} \mathrm{H}$ (entry 3 ) the kinetics of the reaction are spectacularly improved: GC monitoring reveals a conversion of $99 \%$ after only 30 minutes of light soaking (for comparison with $\mathrm{BI}_{1} \mathrm{H}$ after 30 min the conversion is $42 \%$ ). The filtrate reveals the spectral features of Bzp-H (Figure S14). This improvement is likely due to the larger driving force of the reductive quenching of $\mathrm{Cl}^{*}$ by $\mathrm{BI}_{2} \mathrm{H}$. Importantly, when light is masked, the conversion stops and restarts when light is restored, insuring the reaction is not photo-initiated. Control experiments confirmed that no reaction occurred in absence of light or $\mathrm{C} 1$, and that plain $\mathrm{Cu}^{+}$was (photo)catalytically inactive (entries 4,5 and 6 respectively). In the absence of $\mathrm{BI}_{2} \mathrm{H}$, no reaction occurred proving that TEA (entry 1) cannot play the role of sacrificial donor. Traditional 
donor Hantzsch ester (HE) (entry 7) showed very little efficiency compared to $\mathrm{BI}_{1} \mathrm{H}$ and $\mathrm{BI}_{2} \mathrm{H}$ because its oxidation potential is too positive to allow RQ with $\mathrm{C} 1 *$. Decamethylferrocene $(\mathrm{dmFc})$ is so far the only reported donor able to reduce $\mathrm{Cl}^{*}$ because $\mathrm{E}\left(\mathrm{dmFc}^{+} / \mathrm{dmFc}\right)$ is sufficiently low. ${ }^{30,31}$ Yet, attempts with DmFc as D did not work (entry 8) because $\mathrm{dmFc}^{+} / \mathrm{dmFc}$ is a reversible couple, and fast recombination between $\mathrm{Cl}^{-}$and $\mathrm{dmFc}^{+}$prevents accumulation of $\mathrm{Cl}^{-}$. Significantly, when $\mathrm{C} 1$ is replaced by the heteroleptic complex $[\mathrm{Cu}(\mathrm{xantphos})(\mathrm{dmp})]^{+}(\mathrm{C} 2$, Figure S1) the reaction is slowed down because the heteroleptic complex is less sensitive to visible light $\left(\varepsilon_{450 \mathrm{~nm}} \approx 100 \mathrm{~L} \cdot \mathrm{mol}^{-1} \cdot \mathrm{cm}^{-1}\right.$, figure S1) (entry 9). This is more blatant when the dehalogenation reaction is driven with a longer wavelength light source (green LED at $550 \mathrm{~nm}$ ). While the reaction is still successful when the photocatalyst is C1 (entry 9), it is significantly impeded when $\mathrm{C} 1$ is replaced by $\mathrm{C} 2$ (entry 11). $\mathrm{C} 1$ still features a significant absorbance at this wavelength $\left(\varepsilon_{550 \mathrm{~nm}} \approx 230 \mathrm{~L} \cdot \mathrm{mol}^{-1} \cdot \mathrm{cm}^{-1}\right)$ compared to $\mathrm{C} 2\left(\varepsilon_{550 \mathrm{~nm}} \approx 10 \mathrm{~L} \cdot \mathrm{mol}^{-1} \cdot \mathrm{cm}^{-1}\right.$, figure S1), rationalizing the different performances of the two photosensitizers. Finally, under simulated solar light (entry 12), the reaction performed with $\mathrm{C} 1$ was successful. Rewardingly, C1 outperforms classical $\left[\mathrm{Ru}(\mathrm{bpy})_{3}\right]^{2+}$ complex used as PS in the same conditions (entries 13 and 14) proving the relevance of using homoleptic copper complexes to drive challenging reduction reaction. Furthermore, we tested the reaction with only one equivalent of $\mathrm{BI}_{2} \mathrm{H}$. The reaction is still very efficient (entry 15) although slower than the case when two equivalents were used (entry 3). At the end of each run, we could simply recover $\left[\mathrm{BI}_{1}{ }^{+}, \mathrm{Br}^{-}\right]$and $\left[\mathrm{BI}_{2}{ }^{+}, \mathrm{Br}^{-}\right]$by filtration of the photolyzed solution. In the case where only one equivalent of $\mathrm{BI}_{2} \mathrm{H}$ was used (entry 15), $70 \mu \mathrm{mol}$ of $\left[\mathrm{BI}_{2}{ }^{+}, \mathrm{Br}^{-}\right]$were collected showing that $70 \%$ of the initial loading of donor can be restored. We could regenerate $\mathrm{BI}_{1} \mathrm{H}$ and $\mathrm{BI}_{2} \mathrm{H}$ from corresponding collected benzimidazolium by treatment with $\mathrm{NaBH}_{4}$ in mild conditions, and re-use the compounds in new photochemical 
reactions. ${ }^{41}$ No alteration of the photoconversion efficiencies were noted while using recycled $\mathrm{BI}_{1} \mathrm{H}$ or $\mathrm{BI}_{2} \mathrm{H}$. The fact that the sacrificial donor can be easily regenerated by a cheap chemical is a strong advantage of this photochemical cycle, and demonstrates the overall renewability of this BIH-based photochemical reaction. It is worth noting that the ketone function of $\mathrm{Bzp}-\mathrm{Br}$ was untouched during the photolysis, proving the selectivity of the photochemical process. At the end of each run, no elemental copper was observed in the photolyzed mixtures.

Table 2. Results of the photochemical experiments. Conditions: $\mathrm{C} 1=5 \mathrm{~mol} \%$, [TEA] $=0.95 \mathrm{M}$ in THF, 0.1 mmol Bzp-Br, and 1 or 2 eq.of $\mathrm{D}$. All counter-anions for complexes are $\mathrm{PF}_{6}^{-}$.

\begin{tabular}{|c|c|c|c|c|c|}
\hline Entry & Catalyst & Donor (D) & Light & Time (h) & 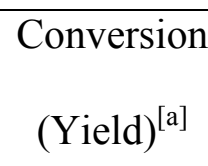 \\
\hline 1 & {$\left[\mathrm{Cu}(\operatorname{dipp})_{2}\right]^{+}, \mathrm{C} 1$} & None & Blue LED & 3 & $0 \%$ \\
\hline 2 & {$\left[\mathrm{Cu}(\operatorname{dipp})_{2}\right]^{+}, \mathrm{C} 1$} & $\mathrm{BI}_{1} \mathrm{H}$ & Blue LED & 3 & $95 \%(89 \%)$ \\
\hline 3 & {$\left[\mathrm{Cu}(\operatorname{dipp})_{2}\right]^{+}, \mathrm{C} 1$} & $\mathrm{BI}_{2} \mathrm{H}$ & Blue LED & 0.5 & $99 \%(93 \%)$ \\
\hline 4 & {$\left[\mathrm{Cu}(\operatorname{dipp})_{2}\right]^{+}, \mathrm{C} 1$} & $\mathrm{BI}_{2} \mathrm{H}$ & None & 3 & $0 \%$ \\
\hline 5 & None & $\mathrm{BI}_{2} \mathrm{H}$ & Blue LED & 3 & $0 \%$ \\
\hline 6 & $\mathrm{Cu}\left(\mathrm{CH}_{3} \mathrm{CN}\right)_{4} \mathrm{PF}_{6}$ & $\mathrm{BI}_{2} \mathrm{H}$ & Blue LED & 3 & $0 \%$ \\
\hline 7 & {$\left[\mathrm{Cu}(\operatorname{dipp})_{2}\right]^{+}, \mathrm{C} 1$} & $\mathrm{HE}$ & Blue LED & 3 & $16 \%$ \\
\hline 8 & {$\left[\mathrm{Cu}(\operatorname{dipp})_{2}\right]^{+}, \mathrm{C} 1$} & $\mathrm{DmFc}$ & Blue LED & 3 & $0 \%$ \\
\hline 9 & {$\left[\mathrm{Cu}(\text { Xantphos })(\mathrm{dmp})_{2}\right]^{+}$,} & $\mathrm{BI}_{2} \mathrm{H}$ & Blue LED & 3 & $85 \%(80 \%)$ \\
\hline
\end{tabular}




\begin{tabular}{|c|c|c|c|c|c|}
\hline & $\mathrm{C} 2$ & & & \\
\hline 10 & {$\left[\mathrm{Cu}(\mathrm{dipp})_{2}\right]^{+}, \mathrm{C} 1$} & $\mathrm{BI}_{2} \mathrm{H}$ & Green LED & 3 & $75 \%(73 \%)$ \\
\hline 11 & $\begin{array}{c}{\left[\mathrm{Cu}(\mathrm{Xantphos})(\mathrm{dmp})_{2}\right]^{+},} \\
\mathrm{C} 2\end{array}$ & $\mathrm{BI}_{2} \mathrm{H}$ & Green LED & 3 & $23 \%$ (n.d. $)^{[\mathrm{b}]}$ \\
\hline 12 & {$\left[\mathrm{Cu}(\mathrm{dipp})_{2}\right]^{+}, \mathrm{C} 1$} & $\mathrm{BI}_{2} \mathrm{H}$ & simulated & 3 & $84 \%(80 \%)$ \\
\hline 13 & $\mathrm{Ru}(\mathrm{bpy})_{3} \mathrm{PF}_{6}{ }^{[\mathrm{cc}]}$ & $\mathrm{BI}_{2} \mathrm{H}$ & Blue LED & 3 & $73 \%$ \\
\hline 14 & {$\left[\mathrm{Cu}(\mathrm{dipp})_{2}\right]^{+}, \mathrm{C} 1^{[\mathrm{c}]}$} & $\mathrm{BI}_{2} \mathrm{H}$ & Blue LED & 0.5 & $99 \%(88 \%)$ \\
\hline 15 & {$\left[\mathrm{Cu}(\mathrm{dipp})_{2}\right]^{+}, \mathrm{C} 1$} & $\mathrm{BI}_{2} \mathrm{H}^{[\mathrm{e}]}$ & Blue LED & 3 & $82 \%(66 \%)$ \\
\hline
\end{tabular}

${ }^{[a]}$ NMR yield with p-anisaldehyde as internal standard ${ }^{[b]}$ Not determined ${ }^{[c]}$ reaction performed in acetonitrile ${ }^{[\mathrm{d}]}$ yield obtained after purification by preparative TLC ${ }^{[e]}$ reaction performed with one equivalent of $\mathrm{D}$.

With the optimized conditions, and to gain more information about the substrates that could be activated under these conditions, we then studied the scope and limitation of the light-mediated, $\mathrm{Cu}(\text { dipp })_{2}{ }^{+}$catalyzed reduction of a series of aryl halides possessing various substituents on the backbone. Reduction of various aryl iodides was first evaluated and found to proceed very rapidly in all cases (less than $1 \mathrm{~h}$, Table 3, entries 2 and 3). Reduction of 4-iodobiphenyl was slower (Table 3, entry 1) likely because it is less activated than 2-iodoacetanilide or 4iodomethylbenzoate. Corresponding deiodinated arenes were obtained in good to excellent yields regardless the substituents on the molecular skeleton of the aryl iodide. The reduction of aryl bromides is more challenging and debromination reactions proceeded more slowly as expected, 
because the $\mathrm{C}-\mathrm{Br}$ bond cleavage kinetics are slower upon aryl bromide reduction. ${ }^{42}$ While the reaction yield was very satisfactory in the case of $\mathrm{Bzp}-\mathrm{Br}$ (Table 2), the conversions and yields dropped for 4-bromomethylbenzoate (Table 3, entries 6 and 7). Conversions are particularly poor for 4-bromo biphenyl and 2-bromo acetanilide (entries 4 and 5) because the substrates were not sufficiently activated. ${ }^{13}$ Finally, almost no conversion was monitored for 4-chlorobenzophenone (Table 3, entry 8), even when irradiation time was prolonged to $12 \mathrm{~h}$. This is likely due to the very challenging $\mathrm{C}-\mathrm{Cl}$ cleavage kinetic rate upon reduction. ${ }^{42}$ Importantly, no conversion was monitored for all substrates in absence of $\mathrm{C} 1$, excepted in the case of 4-iodomethylbenzoate. A conversion of $45 \%$ was observed after $3 \mathrm{~h}$ of irradiation, which is significantly less efficient and more sluggish than in presence of $\mathrm{C} 1$.

Table 3. Scope of the photochemical experiments. Conditions: $\mathrm{C} 1=5 \mathrm{~mol} \%$, $[\mathrm{TEA}]=0.95 \mathrm{M}$ in THF. 0.2 mmol BI $_{2}$ H. 0.1 mmol R-X

\begin{tabular}{|c|c|c|c|c|}
\hline & $\begin{array}{c}\mathrm{R}-\mathrm{X} \\
\mathrm{X}=\mathrm{I}, \mathrm{Br}, \mathrm{Cl}\end{array}$ & $\begin{array}{l}\mathrm{BI}_{2} \mathbf{H}, \text { TEA } \\
{\left[\mathrm{Cu}(\text { dipp })_{2}\right]^{+}} \\
\text {THF, LED }\end{array}$ & $\mathrm{R}-\mathrm{H}$ & \\
\hline Entry & $\mathrm{R}-\mathrm{X}$ & & Time & Conversion (Yield) \\
\hline 1 & & & $3 \mathrm{~h}$ & $73 \%(72 \%)^{[\mathrm{a}]}$ \\
\hline 2 & & & $30 \mathrm{~min}$ & $99 \%(96 \%)^{[a]}$ \\
\hline 3 & & & $1 \mathrm{~h}$ & $99 \%(89 \%)^{[b]}$ \\
\hline 4 & & & $3 \mathrm{~h}$ & $5 \%$ (n.d. $)^{[C]}$ \\
\hline 5 & & & $3 \mathrm{~h}$ & $20 \%$ (n.d. $^{\mid \mathrm{c}]}$ \\
\hline
\end{tabular}




\begin{tabular}{|l|l|l|l|}
\hline 6 & $3 \mathrm{~h}$ & $50 \%$ (n.d.) $^{[\mathrm{c}]}$ \\
\hline 7 & & $3 \mathrm{~h}$ & $55 \%(46 \%)^{[\mathrm{b}]}$ \\
\hline 8 & & $3 \mathrm{~h}$ & $3 \%$ (n.d. $^{[\mathrm{c}]}$ \\
\hline
\end{tabular}

${ }^{[a]}$ NMR yield with p-anisaldehyde as internal standard, ${ }^{[b]} \mathrm{GC}$ yield with hexadecane as internal standard, ${ }^{[\mathrm{c}]}$ Not determined

Based on the gathered experimental facts and on previous works on a similar reaction, ${ }^{13}$ we propose the following mechanism (Scheme 3): photogenerated $\mathrm{C} 1 *$ is efficiently reduced into $\mathrm{C1}^{-}$either by $\mathrm{BI}_{1} \mathrm{H}$ or $\mathrm{BI}_{2} \mathrm{H}$. Bzp-Br is then reduced by $\mathrm{Cl}^{-}$into $\mathrm{Bzp}^{\bullet}$ and $\mathrm{Br}^{-}$thus regenerating C1. Meanwhile, $\mathrm{BI}_{\mathrm{m}} \mathrm{H}^{\bullet+}$ is deprotonated by TEA yielding $\mathrm{BI}_{\mathrm{m}}^{\bullet}$, a strong reductant too $\left(\mathrm{E}_{\mathrm{p} / 2}\right.$ $\left(\mathrm{BI}_{2}^{+} / \mathrm{BI}_{2}{ }^{\bullet}=-1.7 \mathrm{~V}\right.$ vs. SCE, Figure $\left.\mathrm{S} 15\right) . \mathrm{Bzp}^{\bullet}$ is then eventually reduced into carbanion Bzp ${ }^{-}$ either by $\mathrm{Cl}^{-}$(path $\mathrm{A}$ ) or $\mathrm{BI}_{\mathrm{m}}{ }^{\bullet}$ (path $\mathrm{B}$ ), affording $\mathrm{Bzp}-\mathrm{H}$ after protonation. We note than $\mathrm{BI}_{\mathrm{m}}{ }^{\bullet}$ could compete with $\mathrm{C}^{-}$to reduce Bzp-Br too. However, the fact that the reaction is considerably less efficient when $\left[\mathrm{Ru}(\mathrm{bpy})_{3}\right]^{2+}$ is used as a photosensitizer instead of $\mathrm{C} 1$ points to the fact that $\mathrm{Cl}^{-}$is very active in the reduction of the substrates, being a better reductant than $\left[\mathrm{Ru}(\mathrm{bpy})_{3}\right]^{+}$by more than $300 \mathrm{mV}$. Work is ongoing to decipher the full mechanism associated to this completely new photochemical cycle. 


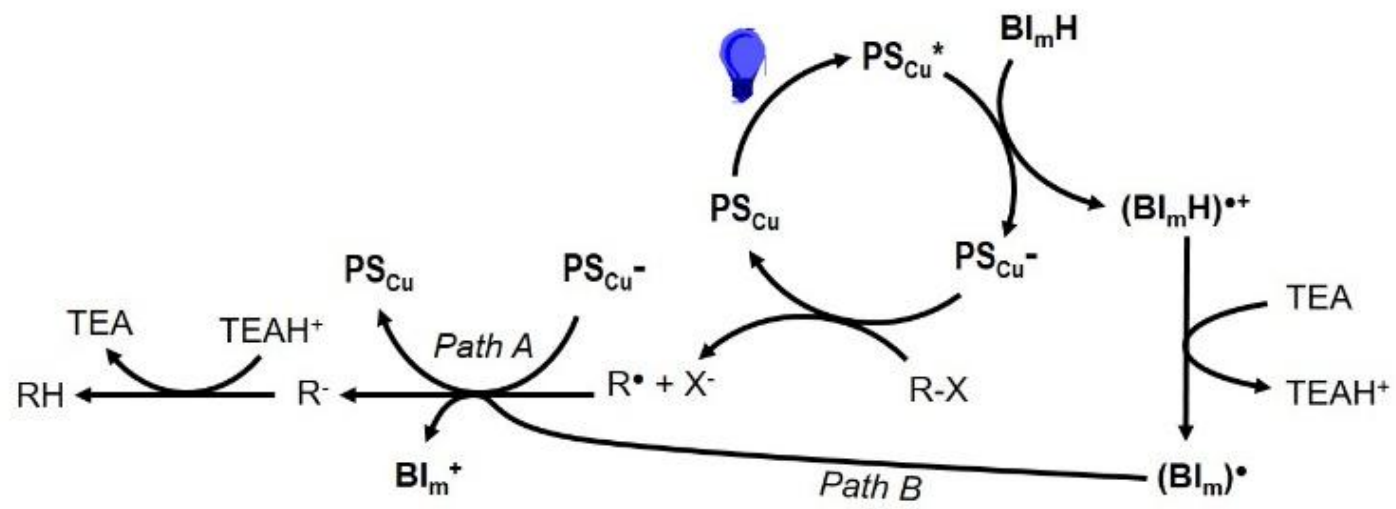

Scheme 3. Supposed mechanism for the photo-induced dehalogenation reaction of R-X

In summary, we synthesized in a few efficient steps new benzimidazoline donors $\mathrm{BI}_{1} \mathrm{H}$ and $\mathrm{BI}_{2} \mathrm{H}$ exhibiting a very strong reductive power. We used them as sacrificial donors in a photochemical cycle and for the first time we were able to monitor the productive reductive quenching of the excited state of a simple and cheap homoleptic copper(I) complex C1 colored in the visible. Using only mild light sources, the strong reductant $\mathrm{Cl}^{-}$was photo-generated in presence of $\mathrm{BI}_{1} \mathrm{H}$ and $\mathrm{BI}_{2} \mathrm{H}$, performing a challenging photo-assisted dehalogenation reaction more efficiently than classical photosensitizers. Importantly, the photo-oxidation of the designed benzimidazoline donors is well controlled and they can be easily regenerated. A preliminary scope study revealed the photochemical process is compatible with many substrates. This work paves the way towards virtually waste-free demanding reduction reactions, driven only by solar energy, with a cheap and essentially non noxious, highly colored homoleptic copper(I) complex.

\section{ASSOCIATED CONTENT}

A supporting Information is available.

\section{AUTHOR INFORMATION}




\section{Corresponding Author}

* E-mail: yann.pellegrin@univ-nantes.fr ; clemence.queffelec@univ-nantes.fr

\section{Author Contributions}

The manuscript was written through contributions of all authors. All authors have given approval to the final version of the manuscript.

\section{Funding Sources}

The authors wish to thank the ANR (PERCO program nANR-16-CE07-0012-01) for financial support.

\section{REFERENCES}

1 N. A. Romero and D. A. Nicewicz, Chem. Rev., 2016, 116, 10075-10166.

2 M. H. Shaw, J. Twilton and D. W. C. MacMillan, J. Org. Chem., 2016, 81, 6898-6926.

3 S. Engl and O. Reiser, ACS Catal., 2020, 10, 9899-9906.

4 A. C. Hernandez-Perez and S. K. Collins, Acc. Chem. Res., 2016, 49, 1557-1565.

5 R. Giereth, M. Obermeier, L. Forschner, M. Karnahl, S. Tschierlei and M. Schwalbe, ChemPhotoChem, , DOI:https://doi.org/10.1002/cptc.202100034.

6 A. Hossain, A. Bhattacharyya and O. Reiser, Science, , DOI:10.1126/science.aav9713.

7 B. M. Hockin, C. Li, N. Robertson and E. Zysman-Colman, Catal. Sci. Technol., 2019, 9, 889-915.

8 J.-M. Kern and J.-P. Sauvage, J. Chem. Soc. Chem. Commun., 1987, 546-548.

9 M. Pirtsch, S. Paria, T. Matsuno, H. Isobe and O. Reiser, Chem. - Eur. J., 2012, 18, 73367340.

10Y. Zhang, M. Heberle, M. Wächtler, M. Karnahl and B. Dietzek, RSC Adv., 2016, 6, 105801105805.

11 B. Wang, D. P. Shelar, X.-Z. Han, T.-T. Li, X. Guan, W. Lu, K. Liu, Y. Chen, W.-F. Fu and C.-M. Che, Chem. - Eur. J., 2015, 21, 1184-1190.

12 A. Call, C. Casadevall, F. Acuña-Parés, A. Casitas and J. Lloret-Fillol, Chem. Sci., 2017, 8, 4739-4749.

13 B. Michelet, C. Deldaele, S. Kajouj, C. Moucheron and G. Evano, Org. Lett., 2017, 19, 35763579 . 
14A. Nitelet, D. Thevenet, B. Schiavi, C. Hardouin, J. Fournier, R. Tamion, X. Pannecoucke, P. Jubault and T. Poisson, Chem. - Eur. J., 2019, 25, 3262-3266.

15H. Baguia, C. Deldaele, E. Romero, B. Michelet and G. Evano, Synthesis, 2018, 50, 30223030.

16O. Green, B. A. Gandhi and J. N. Burstyn, Inorg. Chem., 2009, 48, 5704-5714.

17 S. Garakyaraghi, P. D. Crapps, C. E. McCusker and F. N. Castellano, Inorg. Chem., 2016, 55, 10628-10636.

18 S. Campagna, F. Puntoriero, F. Nastasi, G. Bergamini and V. Balzani, in Photochemistry and Photophysics of Coordination Compounds I, eds. V. Balzani and S. Campagna, Springer, Berlin, Heidelberg, 2007, pp. 117-214.

19D. Hanss, J. C. Freys, G. Bernardinelli and O. S. Wenger, Eur. J. Inorg. Chem., 2009, 2009, 4850-4859.

20 B. J. McCullough, B. J. Neyhouse, B. R. Schrage, D. T. Reed, A. J. Osinski, C. J. Ziegler and T. A. White, Inorg. Chem., 2018, 57, 2865-2875.

21 M. Sandroni, M. Kayanuma, M. Rebarz, H. Akdas-Kilig, Y. Pellegrin, E. Blart, H. L. Bozec, C. Daniel and F. Odobel, Dalton Trans., 2013, 42, 14628-14638.

22 H. Takeda, Y. Monma, H. Sugiyama, H. Uekusa and O. Ishitani, Front. Chem., , DOI:10.3389/fchem.2019.00418.

23 S.-P. Luo, N.-Y. Chen, Y.-Y. Sun, L.-M. Xia, Z.-C. Wu, H. Junge, M. Beller and Q.-A. Wu, Dyes Pigments, 2016, 134, 580-585.

24 A. J. J. Lennox, S. Fischer, M. Jurrat, S.-P. Luo, N. Rockstroh, H. Junge, R. Ludwig and M. Beller, Chem. - Eur. J., 2016, 22, 1233-1238.

25 Y. Sakaguchi, A. Call, M. Cibian, K. Yamauchi and K. Sakai, Chem. Commun., 2019, 55, 8552-8555.

26 M. S. Lazorski and F. N. Castellano, Polyhedron, 2014, 82, 57-70.

27 S. Paria and O. Reiser, ChemCatChem, 2014, 6, 2477-2483.

28 C. Sandoval-Pauker, G. Molina-Aguirre and B. Pinter, Polyhedron, 2021, 199, 115105.

29 N. Armaroli, G. Accorsi, F. Cardinali and A. Listorti, in Photochemistry and Photophysics of Coordination Compounds I, eds. V. Balzani and S. Campagna, Springer, Berlin, Heidelberg, 2007, pp. 69-115.

30 K. L. Cunningham and D. R. McMillin, Inorg. Chem., 1998, 37, 4114-4119.

31 K. L. Cunningham, C. R. Hecker and D. R. McMillin, Inorganica Chim. Acta, 1996, 242, $143-147$.

32 A. K. I. Gushurst, D. R. McMillin, C. O. Dietrich-Buchecker and J. P. Sauvage, Inorg. Chem., 1989, 28, 4070-4072.

33 M. K. Eggleston, D. R. McMillin, K. S. Koenig and A. J. Pallenberg, Inorg. Chem., 1997, 36, $172-176$.

34 A. Rosas-Hernández, C. Steinlechner, H. Junge and M. Beller, Green Chem., 2017, 19, 23562360 .

35X.-Q. Zhu, M.-T. Zhang, A. Yu, C.-H. Wang and J.-P. Cheng, J. Am. Chem. Soc., 2008, 130, 2501-2516.

36 T. J. Collins, R. D. Powell, C. Slebodnick and E. S. Uffelman, J. Am. Chem. Soc., 1991, 113, 8419-8425.

37H. G. Roth, N. A. Romero and D. A. Nicewicz, Synlett, 2016, 27, 714-723.

38E. M. Espinoza, J. A. Clark, J. Soliman, J. B. Derr, M. Morales and V. I. Vullev, J. Electrochem. Soc., 2019, 166, H3175. 
39J.-H. Shon, D. Kim, M. D. Rathnayake, S. Sittel, J. Weaver and T. S. Teets, Chem. Sci., , DOI:10.1039/D0SC06306A.

40 R. S. Shaikh, S. J. S. Düsel and B. König, ACS Catal., 2016, 6, 8410-8414.

41 S. Rohrbach, R. S. Shah, T. Tuttle and J. A. Murphy, Angew. Chem. Int. Ed., 2019, 58, 11454-11458.

42 C. Costentin, M. Robert and J.-M. Savéant, J. Am. Chem. Soc., 2004, 126, 16051-16057.

\section{Table of Contents}

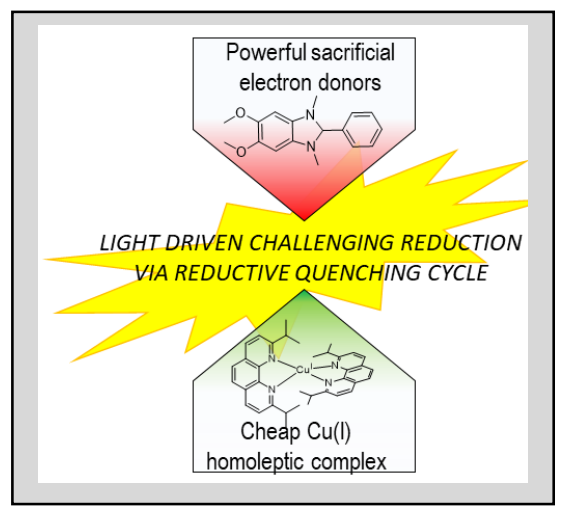

